\title{
Antimicrobial Resources for Disinfection of Potable Water Systems for Future Spacecraft
}

As human exploration adventures beyond low earth orbit, life support systems will require more innovation and research to become self-sustaining and durable. One major concern about future space travel is the ability to store and decontaminate water for consumption and hygiene. This project explores materials and technologies for possible use in future water systems without requiring point-of-use (POU) filtering or chemical additives such as iodine or silver that require multiple doses to remain effective. This experimentation tested the efficacy of a variety of antimicrobial materials against biofilm formation in a high shear CDC Biofilm Reactor (CBR) and some materials in a low shear Drip Flow Reactor (DFR) which also utilizes ultra violet light emitting diodes (UVLEDs) as an antimicrobial resource. Most materials were tested in the CBR using the ASTM E 2562-07 method involving the Pseudomonas aeruginosa and coupon samples that vary in their antimicrobial coatings and surface layer topographies. In a controlled environmental chamber (CEC), the CBR underwent a batch phase, continuous flow phase (CFP), and a harvest before analysis. The DFR portion of this experimentation was performed in order to assess the antimicrobial capabilities of ultraviolet-A LEDs (UV-A) in potable water systems. The ASTM E 2647-08 was modified in order to incorporate UV-A LEDs and to operate as a closed, re-circulating system. The modified DFR apparatus that was utilized contains 4 separate channels each of which contain 2 UV-A LEDs ( 1 chamber is masked off to serve as a control) and each channel is equipped with its own reservoir and peristaltic pump head. The 10 DFR runs discussed in this report include 4 initial experimental runs that contained blank microscope slides to test the UVA LEDs alone, 2 that incorporated solid silver coupons, 2 that utilized titanium dioxide $\left(\mathrm{TiO}_{2}\right)$ coupons as a photocatalyst, and 2 runs that utilized silver coated acrylic slides. Both the CBR and DFR experiments were analyzed for microbial content via heterotrophic plate counts (HPC) and acridine orange direct counts (AODC). Of the materials used in the CBR, only two materials performed as antimicrobials under high shear conditions (a reduction of 5 or more logs) showing a' $>7$ log reduction in viable microbes. However, these antimicrobial materials showed signs of leeching into the water and would need further analysis for safety and health concerns. For the DFR, none of the materials ran with the UV-A LEDs showed enough efficacy to be deemed fit for further implementation. However, these results may have been altered due to the degradation of the LEDs, during the 500 hours of operation, we observed a $41-56 \%$ decrease in the intensity of the utilized LEDs. 


\title{
Antimicrobial Resources for Disinfection of Potable Water Systems for Future Spacecraft
}

\author{
Megan A. Morford ${ }^{1}$ \\ NASA COOP, NASA Engineering-Surface Systems, Kennedy Space Center, Florida, 32899 \\ Michele N. Birmele ${ }^{2}$ \\ Engineering Services Contract, Team QNA, Kennedy Space Center, Florida, 32899 \\ and \\ Michael S. Roberts ${ }^{3}$ \\ Engineering Services Contract, Team QNA, Kennedy Space Center, Florida, 32899
}

This project tested the efficacy of a variety of antimicrobial materials against biofilm formation in a high shear CDC Biofilm Reactor (CBR), some materials in a low shear Drip Flow Reactor (DFR), and in a static environment that utilized UV-A LEDs as the main antimicrobial. Most materials were tested in the CBR using the ASTM E 2562-07 method involving the CBR, Pseudomonas aeruginosa, and coupon samples that vary in their antimicrobial content and surface layer topography. In a controlled environment chamber (CEC), the CBR underwent a batch phase, continuous flow phase (CFP), and a harvest before analysis. Microbial analysis was accomplished by heterotrophic plate counts (HPC) and acridine orange direct counts (AODC) via fluorescent microscopy. The ultimate goal was to identify a material that reduces the amount of microbial biofilm formation without leeching into the water for use in potable water systems for future spacecraft. No materials were successful in the CBR with regards to preventing biofilm formation without leeching and none of the tested materials created enough of a decrease to be considered an antimicrobial (a decrease of 5 -logs is required). However, two antimicrobials were successful by reducing the bacterial load by a $>7-\log$ reduction but they leeched out into the reactor, and would require further testing to be suggested for use and implementation. Overall, of the antimicrobial materials studied within the CBR, none have performed within the required parameters for further implementation. The DFR portion of this experimentation was performed in order to assess the antimicrobial capabilities of ultraviolet-A light-emitting diodes (UV-A LEDs) in potable water systems. An American Society for Testing and Materials Drip Flow Reactor (ASTM-DFR [Designation: E 2647 08]) was modified in order to incorporate UV-A LEDs and to operate as a closed, recirculating system. The modified DFR apparatus that was utilized contains 4 separate channels each of which contain 2 UV-A LEDs ( 1 chamber is masked off to serve as a control) and each channel is equipped with its own reservoir and peristaltic pump head. The 8 DFR runs discussed in this report include 4 initial experimental runs that contained blank microscope slides to test the UV-A LEDs alone, 2 that incorporated solid silver coupons, and 2 runs that utilized a photocatalyst (i.e. titanium dioxide in its anatase form) in order to supplement the inactivation efficacy of the UV-A radiation. Finally, the static portion of experimentation describes the testing of a commercial off-the-shelf, high power Nichia UV-A LED $\left(250 \mathrm{~mW} \lambda_{365 \mathrm{~mm}}\right)$ for the excitation of titanium dioxide as a point-of-use (POU) disinfection device in a potable water system. The combination of an immobilized, high surface area photocatalyst with a UV-A LED is promising for potable water system disinfection since toxic chemicals and resupply requirements are reduced. No additional

\footnotetext{
${ }^{1}$ NASA COOP, NASA Engineering Directorate-Surface Systems, Cal Poly San Luis Obispo.

${ }^{2}$ Research Scientist, Engineering Services Contract, Team QNA, ESC-24.

${ }^{3}$ Sustainable Systems Applied Research Lead, Engineering Services Contract, Team QNA, ESC-24.
} 
consumables like chemical biocides, absorption columns, or filters are required to disinfect and/or remove potentially toxic disinfectants from the potable water prior to use. Experiments were conducted in a static test stand consisting of a polypropylene microtiter plate containing $3 \mathrm{~mm}$ glass balls coated with titanium dioxide. Wells filled with water were exposed to ultraviolet light from an actively-cooled UV-A LED positioned above each well and inoculated with six individual challenge microorganisms recovered from the International Space Station (ISS): Burkholderia cepacia, Cupriavidus metallidurans, Methylobacterium fujisawaense, Pseudomonas aeruginosa, Sphingomonas paucimobilis, and Wautersia basilensis. Exposure to the Nichia UV-A LED with photocatalytic oxidation resulted in a complete $(>7-\log )$ reduction of each challenge bacteria population in $<180$ minutes of contact time.

\begin{tabular}{|c|c|c|}
\hline$\lambda$ & $=$ & wavelength \\
\hline$<$ & $=$ & less than \\
\hline$\leq$ & $=$ & less than or equal to \\
\hline$>$ & $=$ & greater than \\
\hline$\geq$ & $=$ & greater than or equal to \\
\hline${ }^{\circ} \mathrm{C}$ & $=$ & degress Celsius \\
\hline Ag & $=$ & silver \\
\hline $\mathrm{AgF}$ & $=$ & silver fluoride \\
\hline $\mathrm{AM}$ & $=$ & antimicrobial material \\
\hline amp & $=$ & ampere \\
\hline $\mathrm{AO}$ & $=$ & acridine orange \\
\hline AODC & $=$ & acridine orange direct count \\
\hline ASTM & $=$ & American Standard Test Methods \\
\hline CBR & $=$ & CDC biofilm reactor \\
\hline CEC & $=$ & Controlled environment chamber \\
\hline CDC & $=$ & Center for Disease Control \\
\hline CFP & $=$ & Continuous Flow Phase \\
\hline COTS & $=$ & commercial off-the-shelf \\
\hline DI & $=$ & deionized \\
\hline DNA & $=$ & deoxyribonucleic acid \\
\hline ECLS & $=$ & environmental control and life support \\
\hline $\mathrm{eV}$ & $=$ & electron volts \\
\hline g & $=$ & grams \\
\hline HOMO & $=$ & highest occupied molecular orbital \\
\hline $\mathrm{HPC}$ & $=$ & heterotrophic plate count \\
\hline $\mathrm{I}_{2}$ & $=$ & iodine \\
\hline $\mathrm{ICP}$ & $=$ & inductively coupled plasma \\
\hline In & $=$ & Inconel \\
\hline ISS & $=$ & International Space Station \\
\hline $\mathrm{L}$ & $=$ & liters \\
\hline LB & $=$ & \\
\hline LBS & $=$ & \\
\hline LED & $=$ & light-emitting diode \\
\hline $\log$ & $=$ & logarithm \\
\hline
\end{tabular}

\section{Nomenclature}

$\begin{array}{ll}\mathrm{LP} & =\text { low pressure } \\ \mathrm{LUMO} & =\text { lowest unoccupied molecular orbital } \\ \mathrm{mA} & =\text { milliamps } \\ \mathrm{mg} & =\text { milligrams } \\ \mathrm{mL} & =\text { milliliters } \\ \mathrm{mW} & =\text { milliwatts } \\ \mathrm{NaF} & =\text { sodium Fluoride } \\ \mathrm{NASA} & =\text { National Aeronautics and Space } \\ \mathrm{nm} & =\text { Administration } \\ \mathrm{OES} & =\text { optical emission spectrometer } \\ \mathrm{PBS} & =\text { phosphate buffered saline } \\ \mathrm{PCO} & =\text { photocatalytic oxidation } \\ \mathrm{POU} & =\text { point-of-use } \\ \mathrm{ppb} & =\text { parts per billion } \\ \mathrm{ppm} & =\text { parts per million } \\ \mathrm{PWS} & =\text { potable water systems } \\ \mathrm{R} 2 \mathrm{~A} & =\text { R2 agar } \\ \mathrm{RF} & =\text { radio frequency } \\ \mathrm{RH} & =\text { relative humidity } \\ \mathrm{rpm} & =\text { revolutions per minute } \\ \mathrm{SS} & =\text { Stainless steel } \\ \mathrm{ST} & =\text { surface topographies } \\ \mathrm{Ti} & =\text { titanium } \\ \mathrm{TiO} & =\text { titanium dioxide } \\ \mathrm{TOC} & =\text { total organic carbon } \\ \mathrm{TSB} & =\text { tryptic soy broth } \\ \mathrm{UV} & =\text { ultraviolet } \\ \mathrm{UV}-\mathrm{A} & =\text { ultraviolet light in the A spectrum } \\ \mathrm{UV}-\mathrm{C} & =\text { ultraviolet light in the C spectrum } \\ \mathrm{US} & =\text { United States } \\ \mathrm{V} & =\text { volts } \\ \mathrm{W} & =\text { watts } \\ \mathrm{wk} & =\text { eeek } \\ & \end{array}$

\section{Introduction and Background}

$\mathrm{T}$ The National Aeronautics and Space Administration's (NASA) goal to develop safe and effective technologies for closed-loop life support systems requires a potable water system (PWS) with effective and persistent microbial control but without time and mass consuming upkeep. Currently, water used on 
spacecraft is chemically disinfected using $2-4 \mathrm{mg} / \mathrm{L}$ of iodine or $0.4 \mathrm{mg} / \mathrm{L}$ of ionic silver. These methods have proved effective for minimizing microbial growth but also have their drawbacks. These chemicals have relatively low human toxicity thresholds and lose their efficacy over time, requiring multiple doses to be effective. In addition, iodine has high initial Total Organic Carbon (TOC), has been reported to produce an unfavorable flavor, and requires point-of-use (POU) carbon filtering. POU carbon filtering is suggested to contribute to a 1 to 2 orders of magnitude increase in microbial content if the system is not properly flushed and requires additional equipment to complete (Snyder, 1995). These methods require valuable crew time and the addition of mass to the spacecraft for proper upkeep. Also, incongruent water disinfection methods between the shuttle and the International Space Station (ISS) require additional processes to complete proper and safe water transfers. Ionic silver (used in ISS) and iodine (used in the shuttle) treatments are chemically incompatible and when mixed will precipitate out of solution and lose antimicrobial potency. These disadvantages have led NASA to invest in experimentation for alternative antimicrobial methods, which include the use of polymers, Ultraviolet Light-Emitting Diodes (UV-A LEDs), surface topographies (ST), and antimicrobial material (AM) coatings for use in future spacecraft PWS.

Water presently comprises $65 \%$ of the total mass intake for a crew on a spacecraft and will only become more essential in developing life support systems for long-term human missions beyond low Earth orbit. These systems will require technology that allows for collection, storage, recyclability, and disinfection of water for use and reuse. In addition to maintaining the quality of water for human use, these technologies must minimize mass, power, and resupply requirements. This study explores the disinfection requirements and ways to optimize them for potable water and environmental control systems.

Microbial populations have a wide variation of effects on humans. Some cause infection or disease while others live within us essentially. In addition, microbial populations differ in their optimal and survivable environments. Many factors like temperature, nutrient source, $\mathrm{pH}$ level, oxygen availability, among others, factor into what is considered an optimal environment for microbial populations. In PWS, the main microbial concern is biofilm production. Biofilms are produced on organic or non-organic surfaces when plantonic bacteria adhere to a surface, become sessile, and produce an exopolysaccharide (EPS) matrix. Biofilms are known to persist in low nutrient environments, like water systems, and resist the affects of antimicrobial materials including antibiotics. This resistance results because the material may fail to penetrate beyond the surface layer of the biofilm, the material may be impaired by bacterial waste accumulation or altered environment produced by the biofilm, be trapped and destroyed by biofilm matrix enzymes, and may be inhibited by bacterial expression of biofilm-specific resistance genes. Biofilm formation produces these results in large part due to the concentration of nutrients, easiness of gene flow, and community structure (Haddadin, 2010).

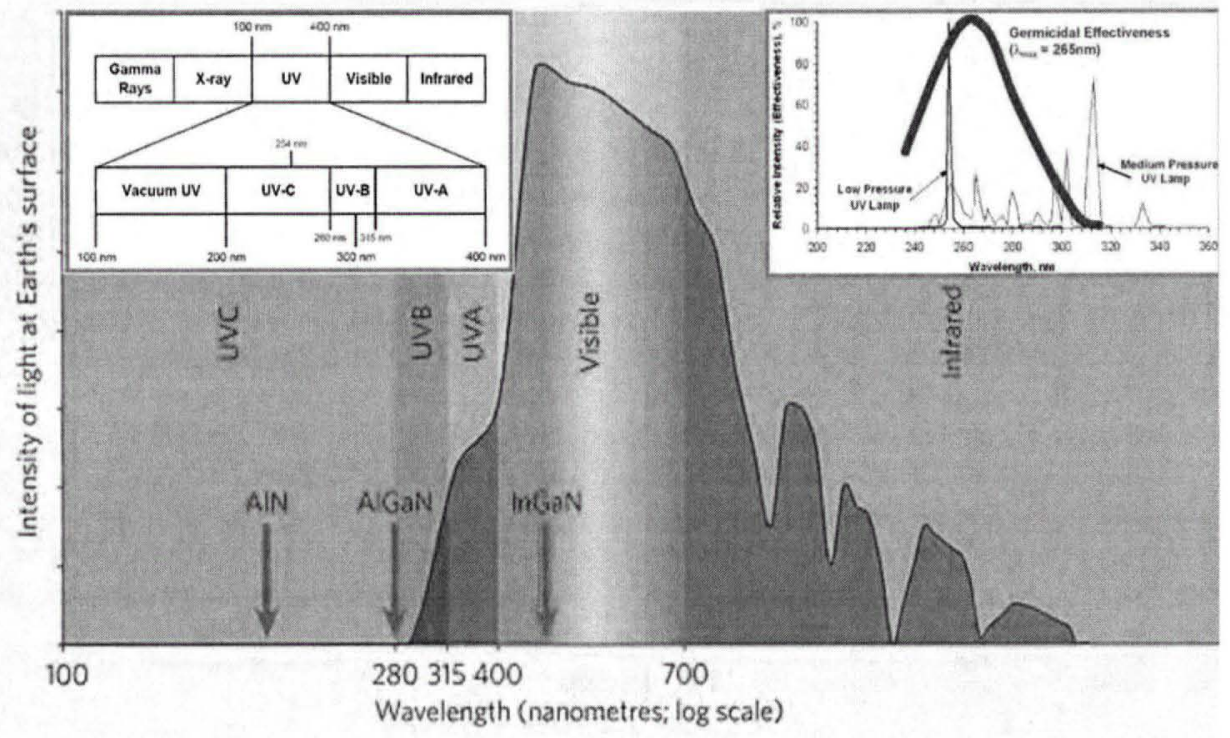

Figure 1. Electromagnetic Spectrum of Ultraviolet Light.

This experimentation explores the utilization of UV-LEDs as an effective antimicrobial. UV-LEDs use less power than mercury UV lamps and have less of a safety hazard associated with them, making UV-LEDs the preferred light source option (Khan, 2006), especially with regards to spaceflight standards. UV-LEDs were chosen 
over mercury UV lamps in part due to the toxicity of mercury. Mercury UV lamps would not pass an engineering safety review due to acute toxicity concerns. ${ }^{10}$ The power consumption in LEDs is also much less than mercury UV lamps; current UV-LEDs use between $250-310 \mathrm{~mW}$ while mercury UV lamps use wattages of $60 \mathrm{~W}$ and higher. ${ }^{7}$ Mercury lamps are relatively efficient at generating UV light in the germicidal spectrum (i.e., peak output at 253.7 $\mathrm{nm}$ for LP lamps, which is near the DNA maximum germicidal absorbance of $265 \mathrm{~nm}$ ), but suffer from a high power penalty. ${ }^{11}$ The range of UV light contains wavelengths between $100-400 \mathrm{~nm}$ which is then divided into 4 (UV specific) ranges (UV-vacuum, C, B, and A) as shown in Fig. $1{ }^{4}$ UV-A was chosen as the UV range because of its availability commercially, and its stability and durability as an LED. UV-A has a longer wavelength (less energy) as compared to other UV-B and UV-C wavelengths, as seen in Figure 1 (Khan, 2006). UV-A LEDs use solid state electronics, do not contain mercury, and are able to emit light near $365 \mathrm{~nm}$; while this is less efficient than the optimal germicidal absorbance of $265 \mathrm{~nm}$, the addition of a photocatalyst can boost the UV-A LEDs' antimicrobial efficacy.

Photocatalysts are materials that have the ability to absorb UV and/or visible light and transfer electrons to neighboring molecules. The electron transfer pathway contains multiple steps. Initially, the photocatalyst absorbs light which excites the ground state electrons from the highest occupied molecular orbital (HOMO) into the lowest unoccupied molecular orbital (LUMO). The electron prefers to be at the lowest possible energy state, therefore, the electron will decay energy levels back to the ground state (i.e. the lowest state). When the neighboring molecule has a LUMO that is lower in energy than that of the catalyst, the electron will transfer to the neighboring molecule rather than decaying back to the original ground state HOMO of the catalyst. The donation of the electron to a neighboring molecule can then be used to catalyze a chemical reaction, generate power, or disrupt biochemical reactions. The band gap of the photocatalyst between the LUMO and HOMO determines the efficiency of the material to donate electrons. The higher the band gap, the more efficient the photocatalyst is at energy generation because more transfer steps can occur before the electron reaches its original ground state. Titanium dioxide is a well-known photocatalyst and in its anatase form has a band gap of $\sim 3.2 \mathrm{eV}$. In this study, we examined both rutile and anatase crystal structures of titanium dioxide with a band gap of around $3.0 \mathrm{eV}$ to promote electron transfer between the material and the bacteria within solution to generate photocatalytic oxidation (PCO). PCO creates free radicals which, in water, can create hydroxyl radicals. These hydroxyl radicals can oxidize organic compounds and add to the effect of UV-A light. ${ }^{8}$

Due to the aforementioned reasons, various experiments have been performed to test the viability of UVLEDs as a low-power disinfection method for potable water systems in both terrestrial and space applications. ${ }^{1} \mathrm{UV}$ light breaks down DNA, preventing replication and damaging proteins by forming dimers between nucleic acids and ultimately hindering transcription. ${ }^{13}$ This does not immediately kill the microbe but can render it incapable of replication and therefore prevents it from being pathogenic. ${ }^{5}$ UV-A (median $\lambda=365 \mathrm{~nm}$ ) has also shown mutagenic capabilities to damage DNA resulting in effects similar, although decreased in capacity, to UV-C (median $\lambda=265 \mathrm{~nm}$ ). ${ }^{12}$ The microbial inactivation efficacy of UV-A light for disinfection of water is augmented by the addition of photocatalysts (e.g., titanium dioxide) that can be oxidized by UV-A to produce free oxygen radicals that in turn damage microorganisms by attacking proteins in cell membranes. ${ }^{3}$

During this experimentation, high shear water system conditions were tested using the CDC Biofilm Reactor (CBR) in congruence with the ASTM E 2562-07 method, which was slightly modified. This portion of experimentation produced 3 weeks worth of biofilm in 2 days by being subjected to a batch phase and continuous flow phase (CFP), both with limited nutrient resources. This biofilm production allowed for analysis of various polymer materials, antimicrobial material (AM) coatings, and surface topographies (ST) and their ability to prevent or decrease bacterial biofilm formation. In addition to the CBR, a drip flow reactor (DFR) was used to test various antimicrobial materials under low shear water system conditions. The DFR experimentation was derived from the ASTM E 2647-08 method, but experienced many modifications. The modifications made to the original method allowed for incorporation of UV-A LEDs, recirculation of inoculated reservoir fluid, and prevention of stagnation within the reservoir. The final methodology of the DFR preserved the low shear dynamics of the reactor, but eliminated the biofilm formation aspect of the experimentation. A third kind of experimentation, static UV-A LED tests, were also utilized to analyze the rate of microbial deactivation by UV-A LEDs with and without photocatalysts within in a static system.

\section{Methods and Materials}

\section{A. CBR Experimentation}


Materials were tested following ASTM E 2562-07 Method "Standard Test Method for Quantification of Pseudomonas aeruginosa Biofilm Grown with High Shear and Continuous Flow using CDC Biofilm Reactor." The CBR was developed to provide consistent biofilm samples and growth conditions for evaluation of antimicrobial agents, surface treatments, and materials.

The reactor consists of eight rods that can hold up to three samples each, for a total of 24 samples (Fig. 2). Each rod has removable coupons that are made of glass, polycarbonate, or acrylic. These coupons were used to adhere $12 \mathrm{~mm}$-indiameter round antimicrobial materials for testing. The reactor was assembled 10 days in advance of use and then sterilized via ethylene trioxide (ETO). Every reactor was ran in a controlled environmental chamber (CEC) with no light, temperature at $21+/-2^{\circ} \mathrm{C}, 50 \%$ relative humidity, and 400 ppm carbon dioxide.

Each week the CBR was prepared with $500 \mathrm{~mL}$ of 300 $\mathrm{mg} / \mathrm{L}$ TSB and $1 \mathrm{~mL}$ of organism, concentration of $1 \times 10^{8}$ cells $/ \mathrm{mL}$, resulting in a final concentration of $2 \times 10^{5}$ cells $/ \mathrm{mL}$ in the CBR. Once prepared, the CBR underwent a batch phase, where it was placed on a stir plate at $130 \mathrm{rpm}$ for 24 hours. During batch phase, there was no flow through the reactor, the only shear produced was from the stir plate. This provided the optimal conditions for biofilm formation using the limited TSB as the carbon source. After batch phase, the reactor was switched into a continuous flow phase which ran for another 24 hours with $20 \mathrm{~L}$ of $100 \mathrm{mg} / \mathrm{L}$ TSB flowing at $11.7 \mathrm{~mL} / \mathrm{min}$ via a peristaltic pump (Figure 3). After 48 hours of operation, the CBR was terminated and harvested.

During harvest, each $12 \mathrm{~mm}$ coupon was biopsied down to $8 \mathrm{~mm}$, this removed edges that may have been damaged and provided consistent sampling size across samples. Each coupon was first rinsed with $5 \mathrm{~mL}$ of water on each side, then placed into $3 \mathrm{~mL}$ of PBS pH 7.4. This sample then underwent vortexing and ice-water bath sonication for 10 minutes in order to detach any sessile biofilm bacteria. Each sample was then analyzed for biofilm formation, and a sample from the reactor was also processed for comparison between reactor content and coupon content.

\section{B. DFR Experimentation}

The DFR was modified to facilitate the use of UV-A LEDs. This was accomplished by replacing the chamber covers with a board that allows for LED placement and light transmittance, as seen in Figure 4 and 5. In addition to the DFR test stand, the effluent ports were modified to flow into individual $50 \mathrm{~mL}$ collection tubes which also act as the reservoirs for each chamber, as seen in Figure 5. The $50 \mathrm{~mL}$ collection tube has two unsealed ports in the lid, one that necessitates the effluent tube, a larger tube made of 24 " Tygon, and one that necessitates the afferent tube, a smaller tube made of 14" Tygon, or 14" Silicone. The afferent tubes run from the reservoirs, through peristaltic pumps, and then into the top of the DFR test stand. This setup allows for a recirculating system, and limited UV-A exposure.

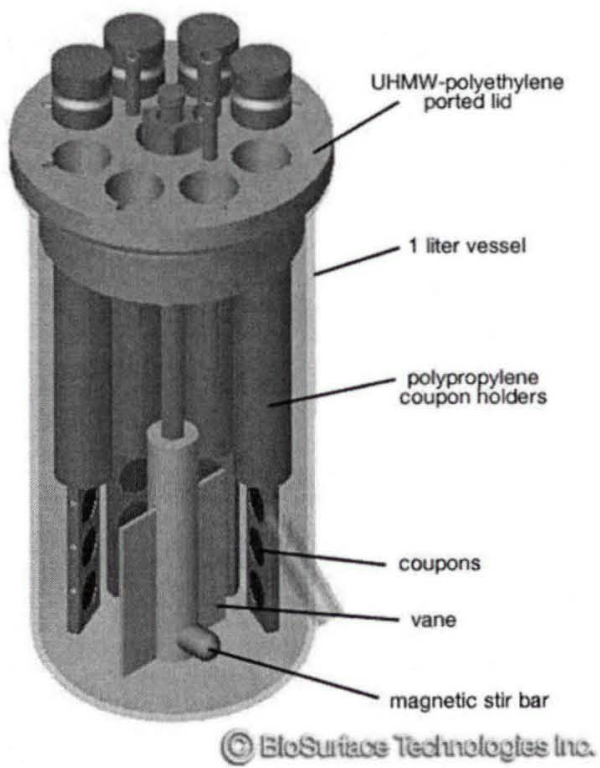

Figure 2. CDC Biofilm Reactor. This is a depiction of the exact Biofilm Reactor used during experimentation. Note the coupon position on rods. During the reaction the sample was facing the interior of the reactor.

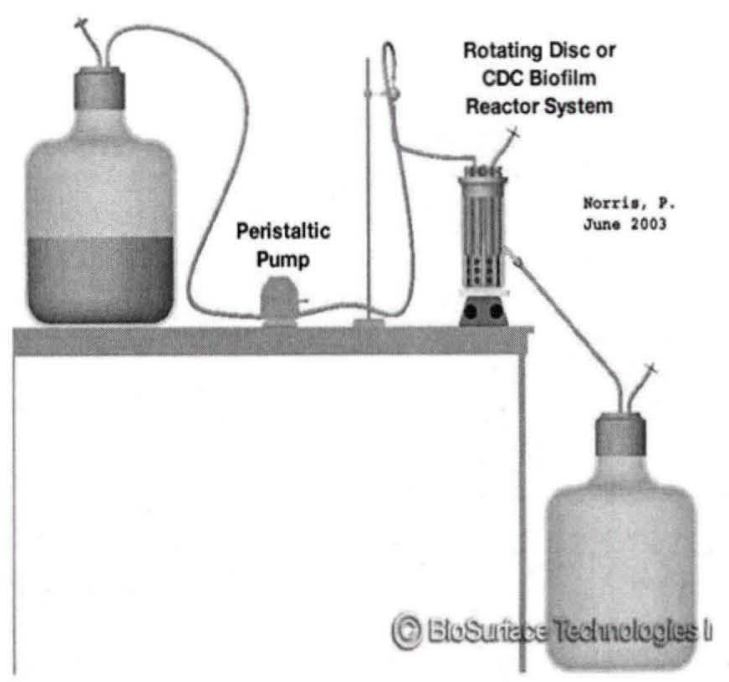

Figure 3. CDC Reactor System. This provides a basic schematic of the system set up to run the reactor on a weekly basis. The carboy on the right contains $100 \mathrm{mg} / \mathrm{L}$ TSB that flows through the reactor during the continuous phase into the carboy on the left. The reactor is placed on the stir plate and is run at the $130 \mathrm{rpm}$ during both batch phase and continuous phase. 


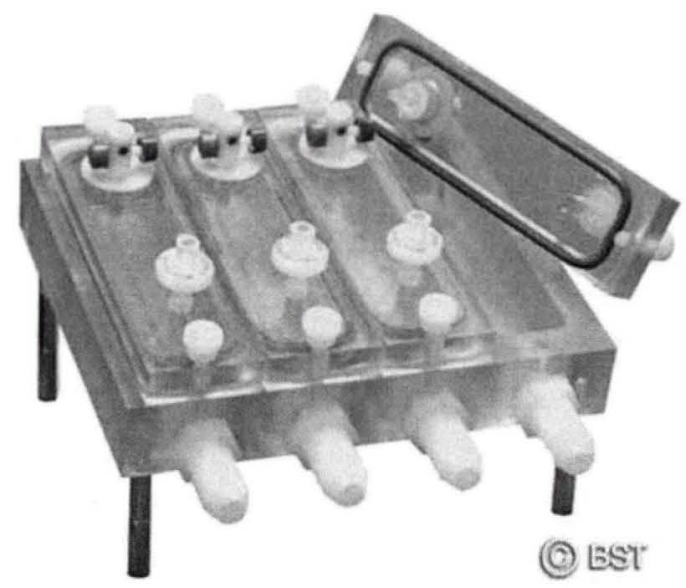

Figure 4. Original Bio Surface Technologies Drip Flow Reactor.
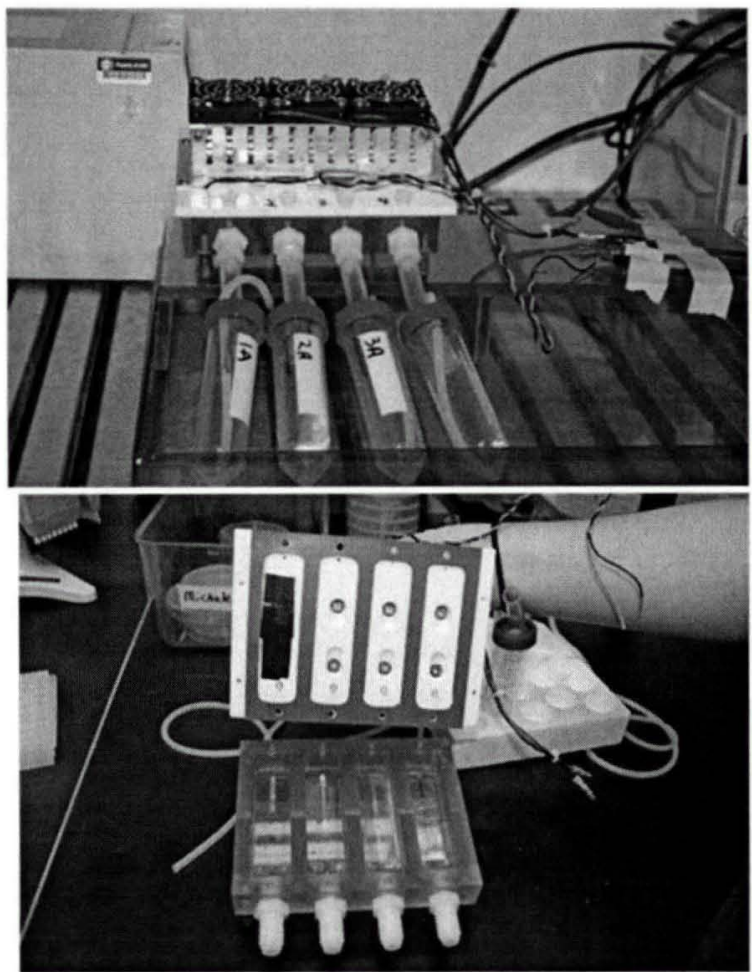

Figure 5. Modified Drip Flow Reactor. (Top) shows the modified drip flow reactor connected to the pump and power source. Note the location of the LEDs on top of the reactor. (Bottom) shows the reactor opened up. Note the solid board, the tape position to serve as the control, and the position of the glass slides within the reactor
During the initial water tests, flow rates identified by the pump were tested. The American Society for Testing and Materials (ASTM) for the DFR (ASTM E 2647-08) indicates flow should be $50 \mathrm{~mL}$ per hour. Each chamber was tested to see if the actual flow rate matched that identified by the pump, and also for the residence time (the time from when the water enters the chamber to when it releases into the effluent tube). Tube lengths for the afferent tubes were also determined and applied to all chambers ( 33.25 inches total, 4.5 inches inserted into the reservoir). The UV-A LEDs were also inspected using a spectroradiometer. UV-A LED 5 on board A and UV-A LED 3 on board B were not functional, so chamber 1 on board $\mathrm{A}$ and chamber 3 on board B were taped off with electrical tape to serve as controls (without UV exposure). Calculations were also done to determine the lowest amount of water needed in the reservoir to run the reactor for a week, get a decent amount of exchanges $(\sim 10)$ per hour, and take $10-300 \mu \mathrm{L}$ samples periodically. After the initial measurements and water tests, the DFR was assembled and sterilized by ETO one week prior to use.

Static tests have shown a greater than 7-log reduction of viable cells (of multiple organisms including Pseudomonas aeruginosa, which is one of the test organisms studied in this experiment) in less than ninety minutes of exposure time to the UV-A LEDs with no photocatalyst or solid silver present. ${ }^{7}$ This has been used as a target time of the minimum exposure required for the microbes to be inactivated. Figure 5 features a red line at the ninety minute mark and illustrates the total theoretical UV-A exposure times of DFR runs 1-8. These were calculated using measured values for the entire volume of fluid in the reactor, flow rate, the residence time/UV-A contact time of the fluid in the chamber, the residence time of the entire apparatus including reactor, reservoir, and tubing, and the total reactor runtime. DFRs 1 and 2 were run with $100 \mathrm{~mL}$ of inoculum in each reservoir, for 96 hours and 122 hours respectively, resulting in a significantly lower total amount of contact time. In order to increase exposure and minimize the possibility and effect of stagnant water in the reservoirs, DFR 3 was run with 12.5 $\mathrm{mL}$. This, however, proved to be an insufficient amount between the required sampling throughout the run and any evaporation possibly taking place. DFRs 4-8 all contained $25 \mathrm{~mL}$, with DFRs 4 and 5 having a total runtime of 144 and 168 hours respectively, and the remaining reactors, 6, 7, and 8 , were run for a total of 96 hours each.

The first DFR (DFR 1) run contained clear glass slides, $12.5 \mathrm{~mL}$ of bacteria inoculated water in the reservoir, and operated at a flow rate of $0.7 \mathrm{~mL}$ per minute. The bacteria cultures were prepared the night before in LB broth at 37 degrees celcius for 24 hours. The reservoir for each chamber was inoculated at a microbial concentration of $1.0 \times 10^{7}$. The reactor, once hooked up to the pump and the UV-A LED

power source, was run for a period of 5-7 days in a controlled environment chamber. $300 \mu \mathrm{L}$ samples were taken from a port near the effluent tube at time points $0,1,2,4,6,24,30,48,54,72,96$, and 144 hours (variations of time 
points were used from week to week) using sterile $3 \mathrm{~mL}$ syringes and 1.5 inch long needles for each chamber. Once each sample was extracted it underwent microbial analysis.

DFR 2 was run in the same manner as the first but some fundamental adjustments were made due to unforeseen problems in the first DFR. The volume of inoculated water in the reservoir was adjusted to 25 $\mathrm{mL}$ due to evaporation, and the flow rate was adjusted to $0.6 \mathrm{~mL}$ per minute. Chamber 4 was also not run due to inadequate tube length. Otherwise, samples were taken by the same method at the same time points as mentioned for DFR 1.

DFR 3 was run in the same manner as

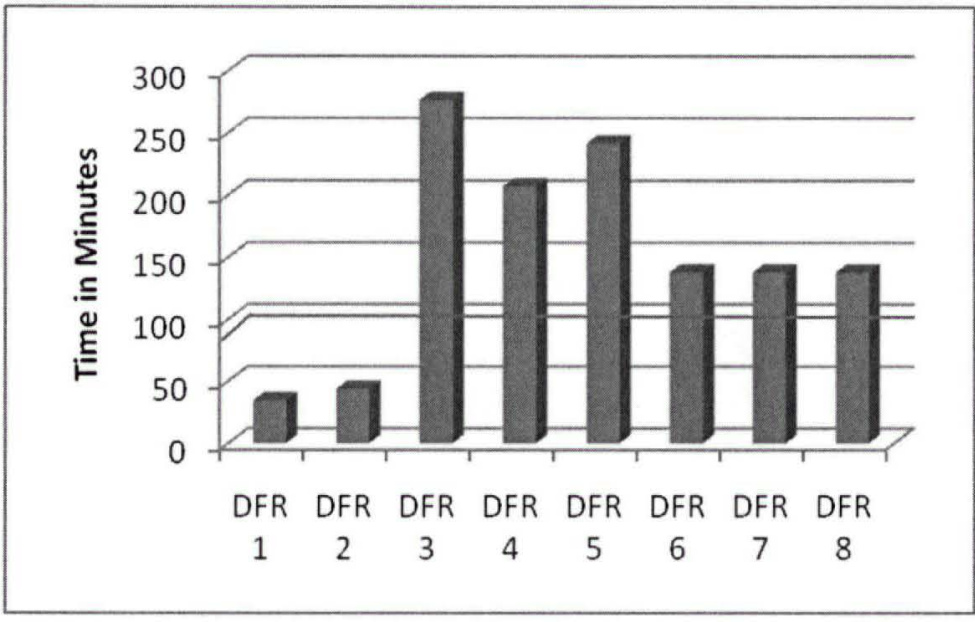

Figure 3. Theoretical UV Contact Times

the second but contained $\mathrm{TiO}_{2}$ coupons and the silicone afferent tubes were replaced with tygon tubing due to damage by the pump. Sampling was conducted in the same manner as mentioned before. At the end of the 7 days, the coupons were then harvested and rinsed with water, placed in $3 \mathrm{~mL}$ of PBS pH 7.4, vortexed, sonicated, vortexed, then diluted for microbial analysis.

The rest of the DFRs were performed in the same fashion as DFR 3. Before each initiation of the reactor residence times for each channel were recorded and at the end of each DFR week actual flow rates were calculated for each channel. The DFR was inoculated with $1 \times 10^{7}$ cells $/ \mathrm{mL}$ of either Pseudomonas aeruginosa (ATCC 10145) or Escherichia coli (ATCC K12).

\section{Static Experimentation}

Two test stands, designated board A and board B according to the particular Nichia UV-A LEDs, were used. An inoculum was prepared by growing each of the test bacterial cells individually in tryptic soy broth (BD, Difco, Franklin Lakes, NJ) and re-suspending them in sterile, deionized water. An inoculum of $1 \times 10^{7}$ cells $/ \mathrm{mL}$ was added in triplicate to a 96 well plate, $2 \mathrm{~mL}$ per well. They were then exposed to each permutation of the treatments while being sampled every 15-30 minutes of exposure time for up to three hours. Control wells were also prepared the same way, but were not exposed to a treatment. Another control test was held in a separate 96 well plate and kept away from the treatment plate to avoid UV exposure. These tests were performed to all of the challenge organisms separately. Duplicate tests were conducted to compare the efficacy of each board. A temperature monitoring experiment was also conducted using a thermocouple while taking measurements of the temperature change over 90 minutes in 15 minute intervals for both boards. All tests were conducted in a controlled environmental chamber set at 20 degrees Celsius, $50 \%$ humidity, and $400 \mathrm{ppm} \mathrm{CO}$.

\section{Coupon Materials}

A variety of antimicrobial materials were used in conjunction with the coupon polymer material and surface topographies (ST) (also seen in Appendix). All reactors contained smooth coupon samples and ST samples. When additional antimicrobial materials were utilized, the material was generally deposited on both smooth and ST coupons and were then ran with smooth and ST coupons without the material for comparison.

A CBR was ran containing a different combination of polymers and antimicrobial materials and surface topographies. For each CBR, a variety of smooth coupons, patterned coupons, coupons that were patterned with the designated antimicrobial, and coupons that were smooth with the designated antimicrobial were tested. Multiples were used of each coupon sample to allow for replication. Four different polymer coupons were possible in the reactors; polydimethylsiloxane (PDMS), polystyrene (PS), polycarbonate (PC) and acrylic. These polymers allow for surface topographies to be imprinted into them and then antimicrobial additives to be applied. Table 1 indicates the combination of coupon polymer material, surface topography, reactor coupon material, and antimicrobial coating used in each CBR $(\mathrm{n}=43)$.

CBR 1- CBR 5 did not utilize any antimicrobial coatings, only the surface topography technology, in this case ST 1 (patterned). CBR 6 used coupons with the antimicrobial 1 (AM 1) (silanol). CBR 7- CBR 10 did not utilize any antimicrobial coatings, only ST 1, but on smaller diameter coupons. CBR 11 utilized AM 1(silanol) that were 
applied at varying application lengths (1 hour, 1 week, 31 hours, and 31 weeks). CBR 12 exhibited ST 1 on PDMS. CBR 13 utilized a 24 hour test antimicrobial. CBR 14 contained coupons (PC,SS, Ti, PP) with a peptide test with a 24 hour time delay. CBR 15 contained coupons (PC, SS, TI, PP) with a peptide test without a time delay. CBR 17 utilized ST 2 on acrylic coupons. CBR 19 utilized ST 2 on PDMS coupons. CBR 21 contained AM 2 (AFRL). CBR 31 contained AM 3 (bioshield) with ST 2. CBR 33 contained AM 4 (ceragenix) with ST 2. CBR 35 contained AM 5 (goldshield spin coated with quaternary ammonium) with ST 2. CBR 36 contained coupons with just ST 3. CBR 37 contained AM 6 ( Triethylsilanol) with ST 2. CBR 37 contained coupons with AM 7 (Nimbus) and ST 2. CBR 40 contained AM 8 (POSS). CBR 41 contained AM 9 (Anish hydrophobic coating). CBR 43 contained AM 10 (hydrophobic never wet). CBR 44 contained AM 11 (Aerogel)

DFRs containing coupons contained $12 \mathrm{~mm}$ in diameter $\mathrm{Ti}_{2}$ coupons. These coupons were placed on the midline of the slide, $2 \mathrm{~cm}$ below the top edge of the slide, directly under the effluent port of the DFR.

Table 1. CBR Contents

\begin{tabular}{|c|c|c|c|c|c|}
\hline Reactor & Organism & Reactor Coupon & $\begin{array}{l}\text { Sample Coupon } \\
\text { Polymer }\end{array}$ & $\begin{array}{l}\text { Surface } \\
\text { Topography }\end{array}$ & Antimicrobial \\
\hline 1 & Pa ERCl & & & 1 & - \\
\hline 2 & Pa ERC1 & & & 1 & - \\
\hline 3 & $\mathrm{~Pa}$ ERCl & & $\mathrm{PC}$ & 1 & - \\
\hline 4 & F5 & & $\mathrm{PC}$ & 1 & - \\
\hline 5 & F5 & & $\mathrm{PC}$ & 1 & - \\
\hline 6 & $\mathrm{~Pa}$ ERC1 & & PC & 1 & 1 \\
\hline 7 & Pa ERC1 & & $\mathrm{PC}$ & 1 & - \\
\hline 8 & Pa ERC1 & & $\mathrm{PC}$ & 1 & - \\
\hline 9 & F5 & & $\mathrm{PC}$ & 1 & - \\
\hline 10 & F5 & & $\mathrm{PC}$ & 1 & - \\
\hline 11 & Pa ERC1 & & $\mathrm{PC}$ & 1 & 1 \\
\hline 12 & $\mathrm{~Pa}$ ERC1 & Glass & PDMS & 1 & - \\
\hline 13 & Pa ERC1 & & & & \\
\hline 14 & $\mathrm{~Pa}$ ERC1 & & PC, SS, Ti, PP & & \\
\hline 15 & $\mathrm{~Pa}$ ERC1 & & PC, SS, Ti, PP & & \\
\hline 17 & $\mathrm{~Pa}$ ERC1 & $\mathrm{PC}$ & Acrylic & 2 & \\
\hline 19 & $\mathrm{~Pa}$ ERC1 & Glass & PDMS & & \\
\hline 21 & $\mathrm{~Pa}$ ERC1 & & & & 2 \\
\hline 31 & $\mathrm{~Pa}$ ERC1 & Glass & PDMS & 2 & 3 \\
\hline 32 & Pa ERC1 & Glass & PDMS & & \\
\hline 33 & $\mathrm{~Pa}$ ERC1 & Glass & PDMS & 2 & 4 \\
\hline 34 & $\mathrm{~Pa}$ ERC1 & Glass & PDMS & & \\
\hline 35 & Pa ERC1 & Glass & PDMS & 2 & 5 \\
\hline 36 & Pa ERC1 & & PS & 3 & - \\
\hline 37 & $\mathrm{~Pa}$ ERC1 & Glass & PDMS & 2 & 6 \\
\hline 38 & $\mathrm{~Pa}$ ERC1 & $\mathrm{PC}$ & ACRYLIC & 2 & 7 \\
\hline 40 & $\mathrm{~Pa}$ ERC1 & & & 2 & 8 \\
\hline 41 & Pa ERC1 & & & 2 & 9 \\
\hline 43 & $\mathrm{~Pa}$ ERC1 & & & 2 & 10 \\
\hline 44 & $\mathrm{~Pa}$ ERC1 & PC & & - & 11 \\
\hline 45 & Pa ERC1 & & & & \\
\hline 46 & Pa ERC1 & & & & \\
\hline
\end{tabular}




\section{E. UV-A LEDs and Titanium Dioxide}

The specifications for the UV-A LEDs used in the static test experiments are described in Fig. 2 and Fig. 3. The UV-A LEDs used a current of $300 \mathrm{~mA}$ and voltage of $24 \mathrm{~V}$. The fans used to cool the LEDs were set at $90 \mathrm{~mA}$ and $12 \mathrm{~V}$. Three types of titanium dioxide (Sigma-Aldrich, St. Louis, MO) were used in the static test experiments. Solutions of rutile titanium dioxide were synthesized at concentrations of $40 \mathrm{~g} / \mathrm{L}$ and $4 \mathrm{~g} / \mathrm{L}$ in ethanol (Sigma). The solutions were deposited onto the test wells of separate 96 well plates using an evaporation method. The anatase crystal phase of titanium dioixide used was synthesized into beads via solgel evaporation. 20 anatase beads were placed at the bottom of each test well in a 96 well plate, during the static testing.

\section{F. Lifecycle Performance}

To measure the performance of the UV-A LEDs, the light intensity was measured on an $\begin{array}{llll}\text { Optronics } & \text { Laboratory } & \text { OL } & 754\end{array}$ Spectroradiometer. Measurements were taken before and after exposure to measure the light intensity degradation over time.

\section{G. Challenge Organisms}

All CBR except 4, 5, 9, 10, and 24 utilized Pseudomonas aeruiginosa strain ERC1. CBR $4,5,9,10$, and 24 utilized a mixture of Pseudomonas aeruginosa (ATCC 10145), Sphingomonas paucimobilis (ATCC 29837), Cupriavidus metallidurans (ATCC 43123), Methylobacterium fujisawaense (ATCC 43884), and Burkholderia cepacia (ATCC 25416). The challenge organisms were grown individually in $50 \mathrm{~mL}$ of $10 \%$ TSB $(3 \mathrm{~g} / \mathrm{L}$ TSB) solution at $37^{\circ} \mathrm{C}$ in a stirring incubator for 24 hours prior to CBR initiation. After 24 hours of growth, a spectrophotometer was used to approximate the concentration of organism using an optical density of $590 \mathrm{~nm}$. A final concentration of $1 \times 10^{8}$ cells $/ \mathrm{mL}$ was obtained by re-suspending the culture with nano-filtered,
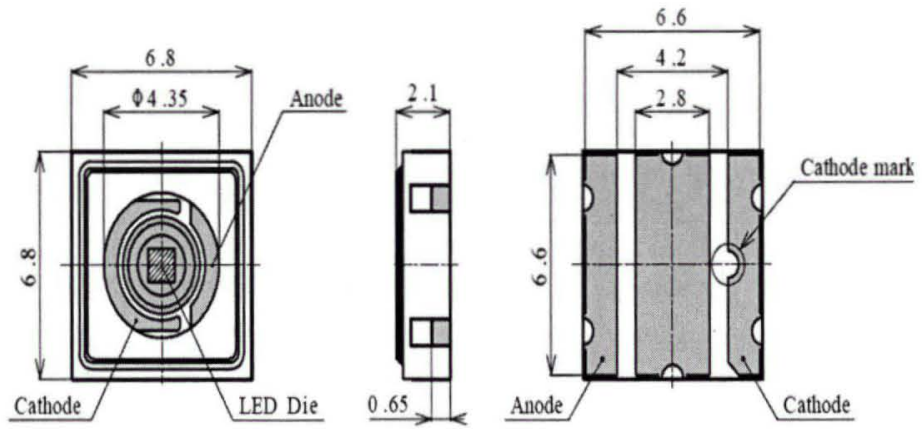

Figure 2. UV-A High Power I-LED; 365 nm; $250 \mathrm{~mW}$ Model NCSU033A (T) Specifications.

\begin{tabular}{|c|c|c|c|c|c|c|c|}
\hline \multicolumn{2}{|c|}{ Item } & Symbol & Condition & Min. & Typ. & Max. & Unit \\
\hline \multirow{3}{*}{ Forward Voltage } & Rank H & \multirow{3}{*}{$V_{F}$} & \multirow{3}{*}{$\mathrm{IF}=500[\mathrm{~mA}]$} & 4.0 & $\cdot$ & 4.4 & \multirow{3}{*}{$\mathrm{v}$} \\
\hline & Rank M & & & 3.6 & - & 4.0 & \\
\hline & Rank L & & & 3.2 & $\cdot$ & 3.6 & \\
\hline Peak Wavelength & Rank Ua & $\lambda \mathrm{P}$ & $\mathrm{IF}=500[\mathrm{~mA}]$ & 360 & (365) & 370 & $\mathrm{~nm}$ \\
\hline \multicolumn{2}{|c|}{ Spectrum Half Width } & $\Delta \lambda$ & $\mathrm{IF}=500[\mathrm{~mA}]$ & - & $(9)$ & $\cdot$ & $\mathrm{nm}$ \\
\hline \multirow{3}{*}{ Radiant Flux } & Rank P7 & \multirow{3}{*}{$\phi \mathrm{e}$} & \multirow{3}{*}{ IF $=500[\mathrm{~mA}]$} & 270 & - & 310 & \multirow{3}{*}{$\mathrm{mW}$} \\
\hline & Rank P6 & & & 230 & . & 270 & \\
\hline & Rank P5 & & & 190 & . & 230 & \\
\hline
\end{tabular}

* Ts: The solder temperature of products (Please refer to the drawing, 090609826792.)

* Forward Voltage Measurement allowance is $\pm 3 \%$.

* Peak Wavelength Measurement allowance is $\pm 3 \mathrm{~nm}$.

$*$ Radiant Flux Measurement allowance is $\pm 10 \%$

Figure 3. UV-A High Power I-LED; $365 \mathrm{~nm} ; 250 \mathrm{~mW}$ Model NCSU033A (T) Specifications. sterile, deionized water. $1 \mathrm{~mL}$ of the final organism concentrate was added to the CBR as the inoculum as per the standard test method. Cultures were grown in duplicate and with a control to monitor initial contamination. For mixed culture challenge communities, the $1 \mathrm{x}$ $10^{8} \mathrm{CFU} / \mathrm{mL}$ suspensions from each of the challenge

organisms were combined and $1 \mathrm{~mL}$ was added as the inoculum to the reactor chamber as per the standard test method.

Six bacterial organisms were chosen for the UV-A static experimentation and were the most likely contaminants of potable water and environmental control life support systems in space due to some of their unique abilities to resist antimicrobials. The challenge organisms include: Burkholderia cepacia (ATCC 25416) Cupriavidus metallidurans (ATCC 43123), Methylobacterium fujisawaense (ATCC 43884), Pseudomonas aeruginosa (ATCC 10145) Sphingomonas paucimobilis (ATCC 29837), and Wautersia basilensis (ISS strain 073130023-1). An inoculum was prepared by growing each of the test bacterial cells individually in tryptic soy broth (BD, Difco, Franklin Lakes, NJ) and re-suspending them in sterile, deionized water. An inoculum of $1 \times 10^{7}$ cells $/ \mathrm{mL}$ was added in triplicate to a 96 well plate, $2 \mathrm{~mL}$ per well.

Pseudomonas aeruginosa (ATCC 10145) or 
Escherichia coli (ATCC K12) were used during DFR experimentation. The challenge organism was grown overnight in a suitable growth media, in this case $10 \%$ TSB $(3 \mathrm{~g} / \mathrm{L})$ for $P$. aeruginosa and $10 \% \mathrm{LBS}(3 \mathrm{~g} / \mathrm{L})$ for $E$. coli After 24 hours of growth, a spectrophotometer was used to approximate the concentration of organism using an optical density of $590 \mathrm{~nm}$. A final concentration of $1 \times 10^{7}$ cells $/ \mathrm{mL}$ was obtained by re-suspending the cultures with nano-filtered, sterile, deionized water. Then $25 \mathrm{~mL}$ was added to each individual reservoir.

\section{H. Microbial Analysis Methods}

A spectrophotometer was employed to (1) measure rapid cellular concentration at $590 \mathrm{~nm}$ and (2) determine the initial concentration of the inoculum. Heterotrophic plate counts (HPC) on R2 agar (R2A) were used to calculate $\mathrm{CFU} / \mathrm{mL}$. Only cells which are able to reproduce can grow on this medium. Acridine orange direct counts (AODC) fixed in $2 \%$ formalin were used to fluorescent-stain live and dead cells. ${ }^{2,6}$ The stained cells were then analyzed and enumerated using a Zeiss Axioskop epi-fluorescent microscope.

Sample coupons, from all applicable experimentation, were prepared for analysis first by vortexing and then icewater bath sonication in $3 \mathrm{~mL}$ of PBS pH 7.4 in order to release the biofilm into the liquid. Each sample, in liquid form (for all three experimentations), was used in a 10-fold dilution series for heterotrophic plate counts (HPC) on R2 agar (R2A). $100 \mu \mathrm{L}$ was applied to each R2A plate from the lowest 3 dilutions and then spread, inverted, and incubated at $37^{\circ} \mathrm{C}$ for 24 hours. After 24 hours, the plates were examined and counted. HPC is used to determine how many microbial colony forming units ( $\mathrm{CFU}$ ) could be recovered after the reactor process, hence indicating the amount of viable cells.

In addition to HPC, acridine orange direct counts (AODC) were performed for all experimentation. $1 \mathrm{~mL}$ of diluted sample was stained with $100 \mu \mathrm{L}$ of acridine orange (AO) for 5 minutes. The sample was then vacuum filtered through a black Millipore filter (). After the filter was dry, the sample was applied to oil on a slide, covered with a drop of oil, and then covered with a cover slip. The slide was then observed using the Zeiss Epi-Fluorescent Axioskop Microscope, and images were saved using DP Controller and DP Manager (Bloem, 1995). The limit of detection for the AODC microscopy is approximately $8.1 \times 10^{3}$ cells $/ \mathrm{mL}$, so counts near this value would be very low. Image-Pro Express 7.0 software was then used to view and count each image. AODCs tend to overestimate the number of total cells in the sample as the stain does not discriminate between DNA from viable cells and that from non-viable cells. In addition, the Image-Pro counter used has approximately a 5-15\% error when counting because it counts all bright objects in the field of view and cannot break apart clumps of cells

\section{Results}

\section{A. CBR Experimentation}

Growing cultures in the $900 \mathrm{mg} / \mathrm{L}$ TSB solution for 24 hours and then measurement with the spectrophotometer proved to be a successful method. As seen in Figure 4, AODC and HPCs show the inoculation levels from this method are consistent from week to week. In general, AODC and HPC results indicate that the CDC reactor performed nominally with minimal variability between experiments.

AM 3 in CBR 31 results show no significant difference between topographies or compounds used in the high shear biofilm reactor in either HPC or AODC. As identified in Figure 5, the concentration of microbes present remained relatively the same across all materials tested. Antimicrobial A did not have any significant difference in the amount of viable cells versus non-viable cells as identified by the similarity between HPCs and AODCs. AM 3 is not effective at high shear levels.

AM 4 (CBR 33) is an opaque compound. Before samples were used, uneven coverage on the coupon surfaces were observed and the samples were identified to be easily damaged. The samples often delaminated and/or sheared during processing, and also filled in the surface topography negating it completely. However, AM 4 did have an antimicrobial impact on the CDC reactor samples with a 7-log+ reduction indicated in the HPCs, as seen in Figure 6. Results indicated that the compound leached into the substrate as no organisms were recovered for the HPCs for both the coupons and the bulk fluid. A few cells were detected during the AODC microscopy on the coupons and in the bulk fluid indicating that the cells were present, but not culturable.

Initially, AM 5 (CBR 35) was applied with 2 methods; a spin coat and a dip coat. The dip coat application was inefficient (the compound was too thick and accumulated in the center of the coupons), so it was discarded and omitted for this series of experimentation. AM 5 also had an antimicrobial impact on the CDC reactor samples with a greater than 3-log reduction indicated on the HPCs for the coupons and a 2-log reduction in the bulk fluid. This reduction was increased on the samples with the patterned surface, as shown in Figure 7. Results indicated that the 
compound leached into the substrate. More cells were present in the AODC samples, again indicating that the cells were intact, but not viable.

The surface topographies (ST 3) that were applied to polystyrene, in CBR 36 were unable to be biopsied due to the fact that they were brittle and broke apart during the process. The full $12 \mathrm{~mm}$ coupons were used for analysis. In addition to being brittle they would not adhere to the reactor coupons, so double sided tape was used to apply the samples to the reactor. That being said, the new patterns did not appear to have an antimicrobial impact on coupon surfaces in the CDC reactor. There was no significant reduction in microbial content for HPCs or AODCs between surface topographies as seen in Figure 8.

One sample from AM 6 (CBR 37) was omitted because of apparent uneven coverage. Also, double sided tape was used to adhere the smooth samples to the reactor coupons. AM 6's HPC and AODC results show no significant difference between topographies or compounds used on antimicrobial impact on coupon surfaces in the CDC reactor. There was no significant reduction in microbial content for HPCs or AODCs as indicated by Figure 9.

\section{B. DFR Experimentation}

\section{Static Experimentation}

The performance of the UV-A LEDs is shown in Fig. 4. According to this data, there were negligible variations between board A and board B, and also between each individual LED after 100 hours of operation. The average decrease was less than $0.01 \%$ between the initial and the endpoint scans.

The temperature of the water increased from $22^{\circ} \mathrm{C}$ to $25^{\circ} \mathrm{C}$ and then leveled out at $25^{\circ} \mathrm{C}$ after 30 minutes for the remainder of testing for both boards. This change in temperature should not have contributed to any loss in cellular viability.

Very little decrease was found before and after exposure to the UV-A LEDs with and without the addition of titanium dioxide according to the AODCs (Table 2). This data supports the theory that the cells were still present in the sample but were no longer culturable. Since the cell membranes were not disrupted, the bacteria would continue to metabolize until cell death, but would be unable to replicate.

UV-A LED exposure effectively disinfected all of the challenge organisms to a non-detectable level within 90 minutes except for Sphingomonas paucimobilis and Methylobacterium fujisawaense, which were only reduced about 1-log. The 4 challenge organisms that were reduced by UV-A alone indicated a 7-log reduction in bacteria populations within the experimental time frame. The UV-A LED with anatase titanium dioxide beads performed similarly to the control UV-A LED exposed samples for the six challenge organisms by killing all measureable bacteria within the inoculums (Fig. 5). In addition, the anatase $\mathrm{TiO}_{2} / \mathrm{UV}-\mathrm{A}$ LEDs had a slightly greater effect on Sphingomonas paucimobilis and Methylobacterium fujisawaense. The test with UV-A and $40 \mathrm{~g} / \mathrm{L}$ of rutile titanium dioxide only yielded a 1-2 log reduction over 120 minutes due to particulates blocking the cellular absorbance of the UV-A. The UV-A with $4 \mathrm{~g} / \mathrm{L}$ of rutile titanium dioxide yielded a 7-log reduction as well, but it took 120 minutes due to particulate shielding the cells. Exposure to titanium dioxide alone yielded a 0.06 log reduction in three hours, which was a very minimal impact.

Table 2. AODC and HPC Results $(n=6)$.
Before exposure
After exposure

\begin{tabular}{ccccc}
\hline Log $(10)$ & AODC $($ cells/mL) & HPC $(\mathrm{CFU} / \mathbf{m L})$ & AODC $(\mathrm{cells} / \mathbf{m L})$ & HPC $(\mathrm{CFU} / \mathrm{mL})$ \\
$\begin{array}{c}\text { Burkholderia } \\
\text { cepacia }\end{array}$ & $6.83 \pm 0.02$ & $6.92 \pm 0.82$ & $6.79 \pm 0.04$ & $0.00 \pm 0.00$ \\
$\begin{array}{c}\text { Cupriavidus } \\
\text { metallidurans }\end{array}$ & $7.13 \pm 0.06$ & $6.97 \pm 1.31$ & $7.12 \pm 0.01$ & $0.00 \pm 0.00$ \\
$\begin{array}{c}\text { Methylobacterium } \\
\text { fujisawaense }\end{array}$ & $6.84 \pm 0.04$ & $6.78 \pm 0.71$ & $6.74 \pm 006$ & $0.00 \pm 0.00$ \\
$\begin{array}{c}\text { Pseudomonas } \\
\text { aeruginosa }\end{array}$ & $7.16 \pm 0.02$ & $6.96 \pm 0.06$ & $7.15 \pm 0.02$ & $0.00 \pm 0.00$ \\
\hline
\end{tabular}




\begin{tabular}{ccccc}
\hline $\begin{array}{c}\text { Sphingomonas } \\
\text { paucimobilis }\end{array}$ & $7.42 \pm 0.01$ & $7.58 \pm 1.12$ & $7.43 \pm 0.04$ & $0.00 \pm 0.00$ \\
$\begin{array}{c}\text { Wautersia } \\
\text { basilensis }\end{array}$ & $7.27 \pm 0.02$ & $7.14 \pm 1.25$ & $7.26 \pm 0.02$ & $0.00 \pm 0.00$ \\
\hline
\end{tabular}

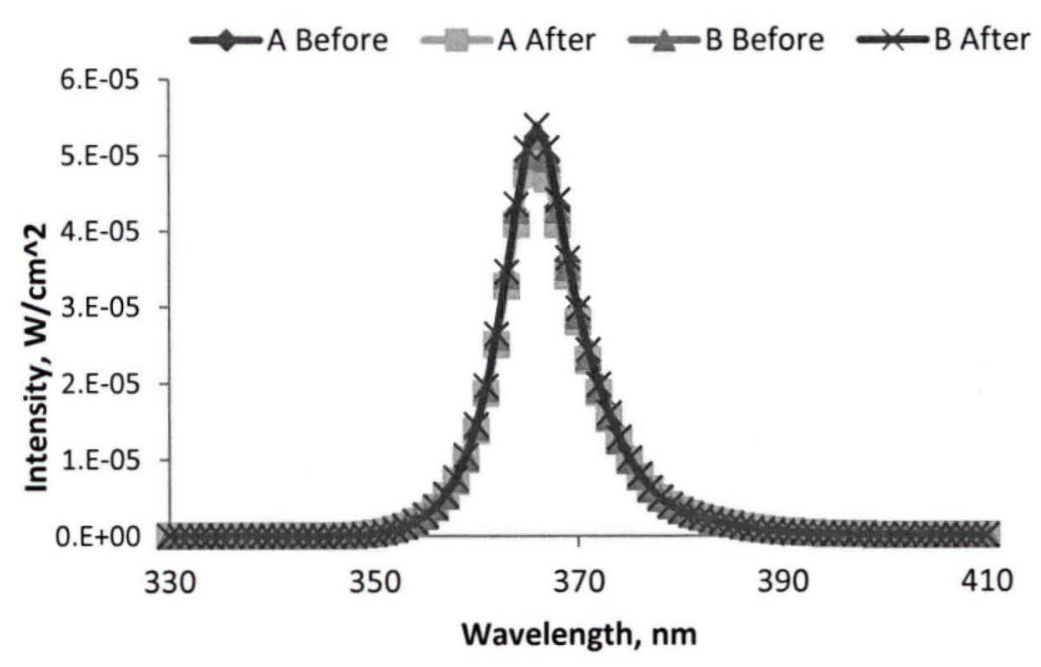

Figure 4. UV-A LED electro-optical performance for Boards $A$ and $B$ in Static test stand.

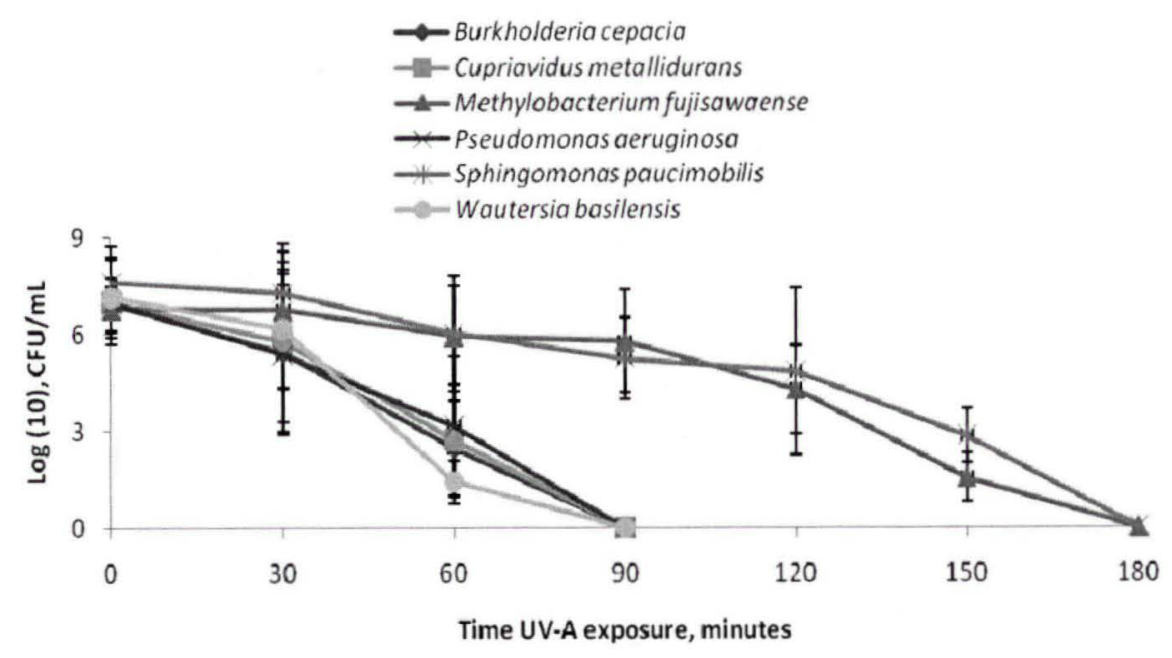

Figure 5. UVA HPC Results. HPC results of all six organisms exposed to $U V-A$ with anatase phase titania $(n=3)$.

\section{Conclusions}

The data from the spectoradiometer showed that there is low variability in intensity between LEDs and between boards. Therefore, in theory, all UV-A LEDs and both boards would have similar efficacy during experimentation. Temperature monitoring for this test stand showed that the UV-A LEDs do not produce enough 
heat to kill the challenge organisms. The AODC was performed to determine the mechanism of cellular degradation. The data showed that the bacteria were not being impacted by cellular membrane rupture caused by the UV-A or the photocatalyst. Rather, it confirmed that the UV-A and titanium dioxide were disrupting replication through DNA degradation. Disrupting cellular replication works as efficiently as rupturing or killing the cells because they are rendered non-pathogenic.

The HPCs revealed that UV-A or UV-A plus titanium dioxide was a very effective disinfection method for static water systems. Out of the six challenge bacteria, the UV-A with anatase titanium dioxide beads was able to reduce Sphingomonas paucimobilis and Methylobacterium fujisawaense more effectively than UV-A alone. This indicated that the titanium dioxide contributed to the disinfection. The rutile titanium dioxide did not perform as well as the anatase beads because the rutile film detached from the walls of the well, floated to the surface of the solution, and blocked the UV-A from penetrating the top of the water. It can also be concluded from these experiments that titanium dioxide without a source of UV light is not effective at disinfection. Furthermore, tests will need to be performed to accurately monitor the formation of oxygen reactive species.

\section{Acknowledgments}

The authors wish to express their sincere appreciation to John Catechis, Griffin Lunn, Richard Meshberger, Jeremy O'neal, and the NASA Life Science Services Contract (NAS10-02001) (Dynamac Corp.) for research support. The authors also wish to thank Dr. Andrew C. Schuerger (University of Florida) for the use of an OL-754 spectroradiometer.

\section{References}

${ }^{4}$ Haddadin, R.N., Saleh, S. A., Mahmoud, R. A., and Shehabi, A. A. "Multiple drug resistance and strength of attachment to surfaces in Pseudomonas aeruginosa isolates," Letters in Applied Microbiology [electronic journal], Vol. 51, pg 48-53, URL: http://www.ncbi.nlm.nih.gov/pubmed/20477963 [published 23 April 2010].

5"Standard Test Method for Quantification of Pseudomonas aeruginosa Biofilm Grown with High Shear and Continuous Flow using CDC Biofilm Reactor," ASTM E 2562-07.

6 "CDC Biofilm Reactor Operator's Manual," BioSurface Technologies Corp.

${ }^{1}$ Birmele, M., McCoy, L., Soler, R., and Roberts, M.S., Ultraviolet Light Emitting Diodes for Disinfection of Spacecraft Potable Water Systems, ICES 2009 09ICES-0083 / 2009-01-2508.

${ }^{2}$ Bloem, J., "Fluorescent staining of microbes for total direct count," In Molecular Microbial Ecology Manual, Vol. 8, Kluwer Academic Publishers, Netherlands, 1995, pp. 1-12.

${ }^{3}$ Giese, N., and Darby, J., "Sensitivity of microorganisms to different wavelengths of UV light: implication on modeling of medium pressure UV systems," Water Research, Vol. 34, No. 16, 2000, pp. 4007-4013.

${ }^{4}$ Hamamoto, A., Mori M., Takahashi, A., Nakaya, Y., and Kinouchi, Y., "New water disinfection system using UV-A lightemitting diodes," Journal of Applied Microbiology, Vol. 103, 2007, pp. 2291-2298.

${ }^{5}$ Hijnen, W.A.M., Beerendonk, E.F., Medema, G.J., "Inactivation credit of UV radiation for viruses, bacteria and protozoan (oo)cysts in water: a review," Water Research, Vol. 40, No. 1, 2006, pp. 3-22.

${ }^{6}$ Hobbie, J.E., Daley, R.J., and Jasper, S., "Use of Nucleopore filters for counting bacteria by fluorescence microscopy," Applied Environmental Microbiology, Vol. 33, 1977, pp. 1225-1228.

${ }^{7}$ Khan, A., "A bug-beating diode," Nature, Vol. 441, 2006, pp. 299.

${ }^{8}$ Liu, B., Wen, L., Zhao, X., "The study of photocatalysis under ultraviolet + visible two-beam light irradiation using undoped nano-titanium dioxide," Materials Chemistry and Physics, Vol. 112, 2008, pp. 35-40.

9 NASA, "Constellation Program Human-Systems Integration Requirements," CxP 70024, Baseline, 2007. (NASA-CxP70024)

${ }^{10}$ NASA, "Man-Systems Integration Standards,” Revision B, July 1995. (NASA-STD-3000)

${ }^{11}$ Naunovic, Z., Lim, S., and Blatchley III, E. R., "Investigation of microbial inactivation efficiency of a UV disinfection system employing an excimer lamp," Water Research, Vol. 42, 2008, pp. 4838-4846. 
12 Runger, T., and Kappes U. P., "Mechanisms of mutation formation with long-wave ultraviolet light (UV-A)," Photodermatology, Photoimmunology \& Photomedicine, Vol. 24, 2007, pp. 2-10.

${ }^{13}$ Vermeulen, N., Keeler, W.J., Nandakumar, K., and Leung, K.T., "The bactericidal effect of ultraviolet and visible light on Escherichia coli," Biotechnology and Bioengineering, Vol. 99, 2008, pp. 550-556.

Snyder, J. W., Mains, C. N., Anderson, R. E., and Bissonnette, G. K., "Effect of Point-of-Use, Activated Carbon Filters on the Bacteriological Quality of Rural Groundwater Supplies," Applied and Environmental Microbiology,Vol.61, No. 12, 1995, pp.

1 NASA, "Constellation Program Human-Systems Integration Requirements," CxP 70024, Baseline, 2007. (NASA-CxP70024)

${ }^{2}$ Naunovic, Z., Lim, S., and Blatchley III, E. R., "Investigation of microbial inactivation efficiency of a UV disinfection system employing an excimer lamp," Water Research, Vol. 42, 2008, pp. 4838-4846.

${ }^{3}$ W.A.M. Hijnen, E.F. Beerendonk, and G.J. Medema, "Inactivation credit of UV radiation for viruses, bacteria and protozoan (oo)cysts in water: A review," Water Research, Vol. 40, 2006, pp. 3-22.

${ }^{4}$ NASA, "Man-Systems Integration Standards," Revision B, July 1995. (NASA-STD-3000)

${ }^{5}$ Khan, A., "A bug-beating diode," Nature, Vol. 441, 2006, pp. 299.

${ }^{6}$ Liu, B., Wen, L., Zhao, X., "The study of photocatalysis under ultraviolet + visible two-beam light irradiation using undoped nano-titanium dioxide," Materials Chemistry and Physics, Vol. 112, 2008, pp. 35-40.

${ }^{7}$ Birmele, M., O’Neil, J., and Roberts, M. Disinfection of Spacecraft Potable Water Systems by Photocatalytic Oxidation Using UV-A Light Emitting Diodes. ICES 2011. NEED MORE INFO 